\title{
The 6 April 2009 earthquake at L'Aquila: a preliminary analysis of magnetic field measurements
}

\author{
U. Villante ${ }^{1,2}$, M. De Lauretis ${ }^{1,2}$, C. De Paulis ${ }^{1,2}$, P. Francia ${ }^{1,2}$, A. Piancatelli ${ }^{1,2}$, E. Pietropaolo ${ }^{1,2}$, M. Vellante ${ }^{1,2}$,

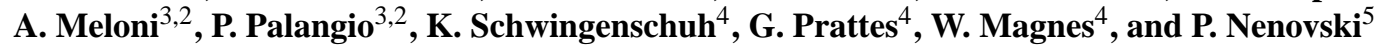 \\ ${ }^{1}$ Dipartimento di Fisica, Università L'Aquila, L'Aquila, Italy \\ ${ }^{2}$ Area di Ricerca in Astrogeofisica, L'Aquila, Italy \\ ${ }^{3}$ Istituto Nazionale di Geofisica e Vulcanologia, Roma, Italy \\ ${ }^{4}$ Institut für Weltraumforschung, Graz, Austria \\ ${ }^{5}$ Geophysical Institute, Sofia, Bulgaria
}

Received: 10 October 2009 - Revised: 21 December 2009 - Accepted: 11 January 2010 - Published: 9 February 2010

\begin{abstract}
Several investigations reported the possible identification of anomalous geomagnetic field signals prior to earthquake occurrence. In the ULF frequency range, candidates for precursory signatures have been proposed in the increase in the noise background and polarization parameter (i.e. the ratio between the amplitude/power of the vertical component and that one of the horizontal component), in the changing characteristics of the slope of the power spectrum and fractal dimension, in the possible occurrence of short duration pulses. We conducted, with conventional techniques of data processing, a preliminary analysis of the magnetic field observations performed at L'Aquila during three months preceding the 6 April 2009 earthquake, focusing attention on the possible occurrence of features similar to those identified in previous events. Within the limits of this analysis, we do not find compelling evidence for any of the features which have been proposed as earthquake precursors: indeed, most of aspects of our observations (which, in some cases, appear consistent with previous findings) might be interpreted in terms of the general magnetospheric conditions and/or of different sources.
\end{abstract}

\section{Introduction}

In the last two decades several papers reported the possible identification of anomalous geomagnetic field signals prior to earthquake occurrence (reviews by Hattori and Hayakawa, 2007; Fraser-Smith, 2008, 2009, and papers therein referenced) and large networks of ground-based instruments

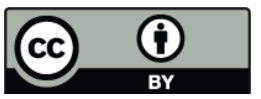

Correspondence to: U. Villante (umberto.villante@aquila.infn.it) and even some satellite-based systems have been recently dedicated to these scopes (Bleier and Freund, 2005; Bleier and Dunson, 2005; Reichhardt, 2003; Parrot and Ouzounov, 2006; Zlotnicki et al., 2006).

In the ultra low frequency range (ULF, $1 \mathrm{mHz}<f<10 \mathrm{~Hz}$ ), emissions preceding strong and destructive earthquakes were originally proposed for the Loma Prieta event $(M=6.9$, according to USGS Catalog; distance of instrumentation from the epicentre, $d \approx 7 \mathrm{~km}$; Fraser-Smith et al., 1990; Bernardi et al., 1991) and further corroborated for other strong earthquakes, such as Spitak $(M=6.8 ; d \approx 128 \mathrm{~km}$; Molchanov et al., 1992; Kopytenko et al., 1993), Guam ( $M=7.8 ; d \approx 65$ km; Hayakawa et al., 1996, 1999; Miyahara et al., 1999; Ida et al., 2005), Biak $(M=8.2 ; d \approx 100 \mathrm{~km}$; Hayakawa et al., 2000), Chia-yi ( $M=7.6$; $d \approx 8 \mathrm{~km}$; Yen et al., 2004), Bovek ( $M=5.2 ; \quad d \approx 153 \mathrm{~km}$; Prattes et al., 2008), Alum Rock ( $M=5.6 ; d \approx 2 \mathrm{~km}$; Bleier et al., 2009), and others. According to these analysis, ULF precursor signals might basically consist of one or more of the following aspects:

- A substantial increase in the noise background starting from days to several weeks preceding earthquake covering almost the entire ULF range (Loma Prieta, Spitak, Guam, Alum Rock), followed by an anomalous dip in the range $0.2-5 \mathrm{~Hz}$ starting one day ahead the earthquake (Loma Prieta).

- An increase to a high level of activity in the range $\approx 10$ $50 \mathrm{mHz}$ starting few hours before the earthquake (Loma Prieta, Spitak).

- A broad maximum of the "polarization parameter" $R^{2}=P_{\mathrm{Z}} / P_{\mathrm{H}}$ about one month before the earthquake $\left(P_{\mathrm{Z}}\right.$ and $P_{\mathrm{H}}$ being the integrated power of the vertical component, Z, and of the North/South component, $\mathrm{H}$, in the

Published by Copernicus Publications on behalf of the European Geosciences Union. 
approximate range of frequency $\approx 10-100 \mathrm{mHz}$; Guam, Bovec) and the emission of presumably earthquake associated waves with main frequency in the range 20$50 \mathrm{mHz}$ (Guam).

- A gradual decrease of the slope of the power spectrum during the process of earthquake preparation (1-1.5 month) and an increase of the fractal dimension (Guam, Biak).

- An increased occurrence of negative or positive (or a combination of positive and negative) pulses of short duration, identified on the East/West component (D) approximately 15 days before the earthquake (Alum Rock).

As a matter of fact, although no firm evidence for a clear association between these features and the earthquake occurrence has yet been provided, all the experimental elements summarized in previous paragraphs have been considered as candidates for precursory signatures (Fraser-Smith, 2009). However, the absence of common features for different events makes controversial the entire subject. On the other hand, the possible detection of precursory signals is obviously expected to be related to the strength and characteristics of the seismic events as well as to the distance of the epicentre from the geomagnetic observatory. Fraser-Smith et al. (1994), who examined the Northridge event $(M=6.7)$, concluded that, assuming that ULF magnetic fields were produced, their amplitudes were too small to produce obvious increases in the ULF background noise at $d \approx 81 \mathrm{~km}$ from the epicentre. Nevertheless, an analysis conducted by Johnston et al. (2006) did not reveal any indication for an ULF activity preceding the Parkfield earthquake $(M=6.0 ; 28$ September 2004) immediately above the hypocenter and along a magnetometric array of $\approx 60 \mathrm{~km}$. In addition, according to Thomas et al. (2009a), the geomagnetic field measurements of the Loma Prieta earthquake (the most frequently cited identification of a magnetic precursor) might be also interpreted in terms of anomalous magnetic signals not related to the earthquake (Thomas et al., 2009b also proposed the absence of anomalous signals at Guam), eventually due to a coincidental geomagnetic solar-terrestrial disturbance (Campbell, 2009).

From a theoretical point of view, several physical mechanisms have been proposed to explain the possible appearance of geomagnetic signals (in general) prior the earthquake occurrence; they include electrokinetic and magnetohydrodynamic effects resulting from fluid motions through the crust, piezomagnetism, stress-induced increase in local crustal conductivity, microfracturing, and others (Draganov et al., 1991; Park, 1993; 1996; Fenoglio et al., 1993, 1995; Johnston, 1997; Merzer and Klemperer, 1997; Molchanov and Hayakawa, 1994, 1995a, 1998; Egbert, 2002; Surkov et al., 2003; Simpson and Taflove, 2005). Basically, however, the expected effects are mainly correlated with the onset of quasi-static magnetic field variations and ULF emissions would eventually appear as transient features.

In this context, given the importance of all the aspects which might be related to the earthquake prediction, we found interesting to provide the results of the ULF measurements conducted close to the epicentre $(d \approx 6 \mathrm{~km})$ during three months preceding the earthquake of 6 April 2009 which devastated L'Aquila (AQU, Italy, $\mathrm{LT}=\mathrm{UT}+1$; geomagnetic coordinates: $36.33^{\circ} \mathrm{N} ; 87.37^{\circ} \mathrm{E}$ ) and its territory (including the Physics Department) and caused more than 300 deaths (including 47 students of the local university). In this preliminary analysis, adopting conventional techniques of data processing, we focus attention on the possible occurrence of features similar to those identified in previous events; more sophisticated analysis of this event and thorough comparisons with simultaneous measurements at other stations will be presented in forthcoming papers.

The central Apennines, that belongs to the Lazio-Abruzzi Mesozoic carbonate platform domain, is dominated by the roll-back of the Adriatic subduction toward the east. This region shows an arc-like belt of seismicity in the upper crust that follows the mountain range and is characterized by normal faults directed along pre-existing compressive tectonic structures (Anzidei et al., 2009). In the Abruzzi sector, mainly calcareous deposits constitute most of the thrust system. Near L'Aquila, an elongated northwest southeast trending intramontane basin is present; its alluvial to lacustrine Quaternary filling deposits are up to $100 \mathrm{~m}$ thick. The deposits are formed mainly by loose gravelly sands interlayered with palustrine silty-clayey lenses and blocky calcareous debris (Rapolla et al., 2009, and papers therein referenced). De Luca et al. (2005) who examined accelerometric recordings of earthquakes with moderate and intermediate magnitude at both local and regional distances, revealed a significant ground-motion amplification effect at low frequencies $(\approx 0.6 \mathrm{~Hz})$ in the city of L'Aquila, consistent with a sedimentary basin, filled by lacustrine sediments, with a maximum depth of about $250 \mathrm{~m}$.

\section{The seismic event and the ULF measurements}

"An earthquake measuring 6.3 on the Richter scale hit central Italy last night causing thousands of people to lose their homes and more than 250 deaths. Most of the damage surrounds the city of L'Aquila, which includes one of the oldest centers of learning in Europe, the University of L'Aquila. More than 4000 buildings in the city have collapsed" (Physics Today, 8 April 2009).

Such earthquake occurred on 6 April 2009, 01:32 UT: according to the Istituto Nazionale di Geofisica e Vulcanologia (INGV), it was classified as an $M_{\mathrm{L}}=5.8, M_{\mathrm{W}}=6.3$ event, with a depth of $8.8 \mathrm{~km}$. It was preceded by a persistent seismic activity for approximately three months: namely, between 16 January and 5 April 2009, 34 seismic events with 
$2<M_{\mathrm{L}}<3$ (and 9 with $M_{\mathrm{L}}>3$ ) were registered in the territory. The main shock (the largest event in this region since the last destructive earthquake occurred in 1703) was followed by a large numbers of aftershocks with remarkable events on 7 April 17:47 UT $\left(M_{\mathrm{L}}=5.3\right)$ and on 9 April 00:52 UT $\left(M_{\mathrm{L}}=5.1\right)$.

At AQU magnetic field measurements are routinely conducted at the Geomagnetic Observatory (INGV) and at the ULF station of the University of L'Aquila. As shown in Fig. 1, the Geomagnetic Observatory/ULF station are located $\approx 6.0 \mathrm{~km}$ from the epicentre of the strongest event. The magnetic field observations presented hereafter are those of the tri-axial fluxgate and induction magnetometers of the ULF station. Measurements from both instruments are recorded at a sampling frequency of $1 \mathrm{~Hz}$ from the same acquisition system. The fluxgate magnetometer has a rms instrumental noise of $\sim 20 \mathrm{pT}$ in the frequency band 1$500 \mathrm{mHz}$; more specifically, according to the usual classification scheme for continuous pulsations (Pc1: $200-500 \mathrm{mHz}$; Pc2: 100-200 mHz; Pc3: 20-100 mHz; Pc4: 7-20 mHz; Pc5: $1-7 \mathrm{mHz}$ ), the rms noise is $\sim 10 \mathrm{pT}$ (Pc1 band), $\sim 10 \mathrm{pT}$ (Pc2), $10 \mathrm{pT}$ (Pc3), 5 pT (Pc4), 3 pT (Pc5). The rms of the quantization noise is $\sim 0.3 \mathrm{pT}$. The induction magnetometer has an amplitude/frequency response almost linear $(\sim 6 \mathrm{~V} / \mathrm{nT} / \mathrm{Hz})$ in the frequency range $0-0.2 \mathrm{~Hz}$. The rms instrumental noise is $\sim 1 \mathrm{pT}(\mathrm{Pc} 1), \sim 1 \mathrm{pT}(\mathrm{Pc} 2), \sim 3 \mathrm{pT}$ (Pc3), $\sim 5 \mathrm{pT}$ (Pc4), $\sim 10 \mathrm{pT}(\mathrm{Pc} 5)$. The rms of the quantization noise is less than $0.5 \mathrm{pT}$ in the frequency range 1$500 \mathrm{mHz}$. According to Villante and Vellante (1998) and Villante et al. (2004), the man-made contamination determines in the ULF bands a weekly modulation with minimum power values on Sundays and reduced power level on Saturdays; such contamination would provide an additional noise during weekdays (daytime hours) of $\sim 1 \mathrm{pT}(\mathrm{Pc} 1), \sim 2 \mathrm{pT}$ (Pc2), $\sim 3 \mathrm{pT}$ (Pc3), while no significant contamination was determined in the lower frequency bands and, in general, during nighttime hours.

In the present analysis data have been organized in frequency bands corresponding to the Pc1-Pc5 classification. For the higher frequency bands (Pc1-Pc2) we will mostly consider measurements from the induction magnetometer, more suitable for higher frequency fluctuations (as confirmed by the rms noise), and measurements from both instruments in the other bands (Pc3-Pc5). The spectra of the geomagnetic field components have been evaluated over 60-min intervals between 1.7 and $500 \mathrm{mHz}$. For the scopes of the present investigation, in each frequency band the polarization parameter $R$ is determined by the ratio between the vertical and the total horizontal signal amplitude, namely $R=\left(P_{\mathrm{Z}} /\left(P_{\mathrm{H}}+P_{\mathrm{D}}\right)\right)^{1 / 2}$. The scale exponent of the magnetic field observations has been evaluated by means of the Detrended Fluctuation Analysis method (DFA), as originally proposed by Peng et al. (1995); in particular, we considered a range of temporal scales from 10 to $500 \mathrm{~s}$ and the fast algorithm developed by Little et al. (2006). A preliminary

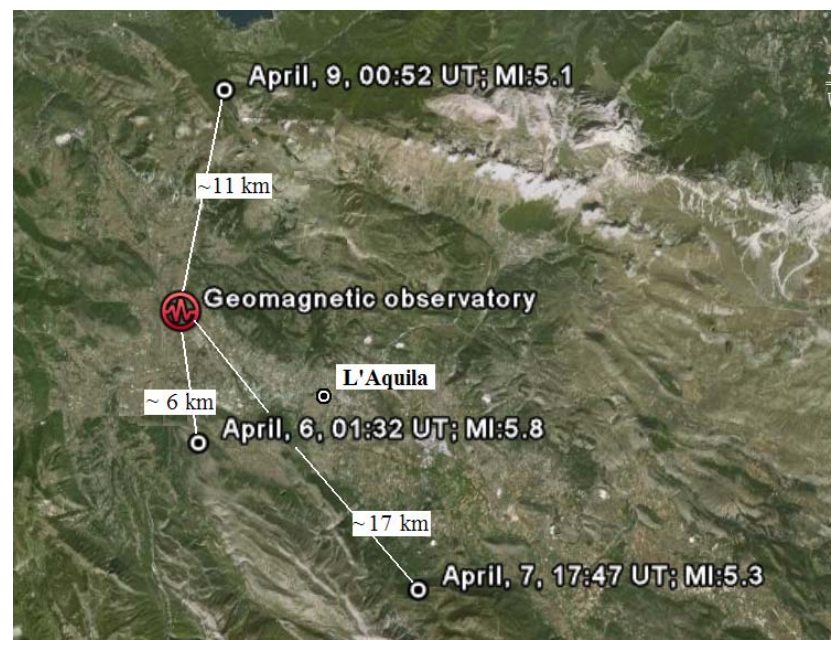

Fig. 1. The position of the epicentre of the major events with respect to the position of the Geomagnetic Observatory and ULF station.

analysis revealed the post-midnight interval 00:00-03:00 UT (01:00-04:00 LT) at AQU as less affected by ULF events of magnetospheric origin (except for the possible occurrence of Pi2 events, 7-25 mHz) and man-made contamination: consequently, as in previous investigations (Hayakawa et al., 1996, 1999; Prattes et al., 2008), we mostly focused our attention on such "quiet" interval for the identification of possible ULF emissions of lithospheric origin.

\section{The experimental observations}

\subsection{The results of a statistical analysis}

In order to identify the possible occurrence of an explicit variation in the amplitude of ULF signals in the time interval preceding earthquake and characterized by a persistent seismic activity, we compared (Fig. 2a-c) the histograms of the amplitude distribution in different frequency bands (00:00-03:00 UT) as obtained during 2007-2008 (we excluded November and December 2008 in that affected, although occasionally, by seismic activity) with those obtained during the three months interval preceding earthquake (2 January-5 April 2009). In general, such histograms show that the $\mathrm{Z}$ component (less influenced by magnetospheric and ionospheric signals), is typically characterized by lower amplitudes with respect to the other components in all frequency bands. The comparison between different intervals does not reveal any statistical evidence for an increased ULF activity preceding the earthquake in any frequency band or component; rather, such observations would suggest a general tendency for a lower ULF activity.

Histograms of the polarization parameter (Fig. 2d) reveal more peaked distributions in the higher frequency bands, with peak values of the order of $\approx 0.2-0.4$ which basically 
(a)

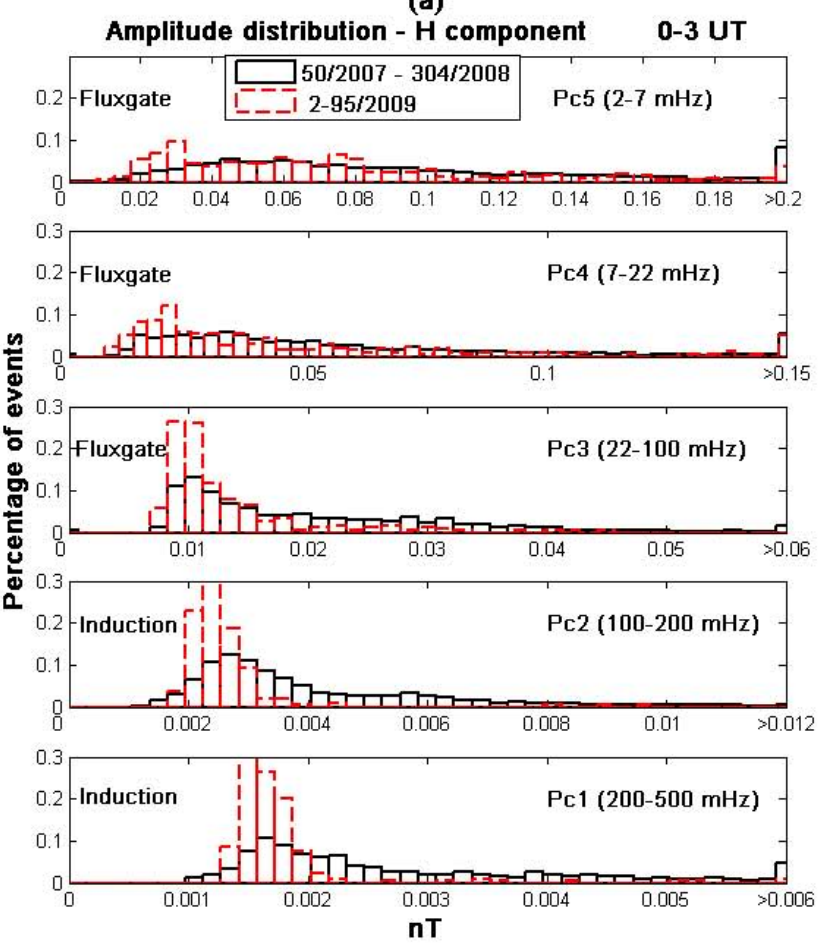

(c)
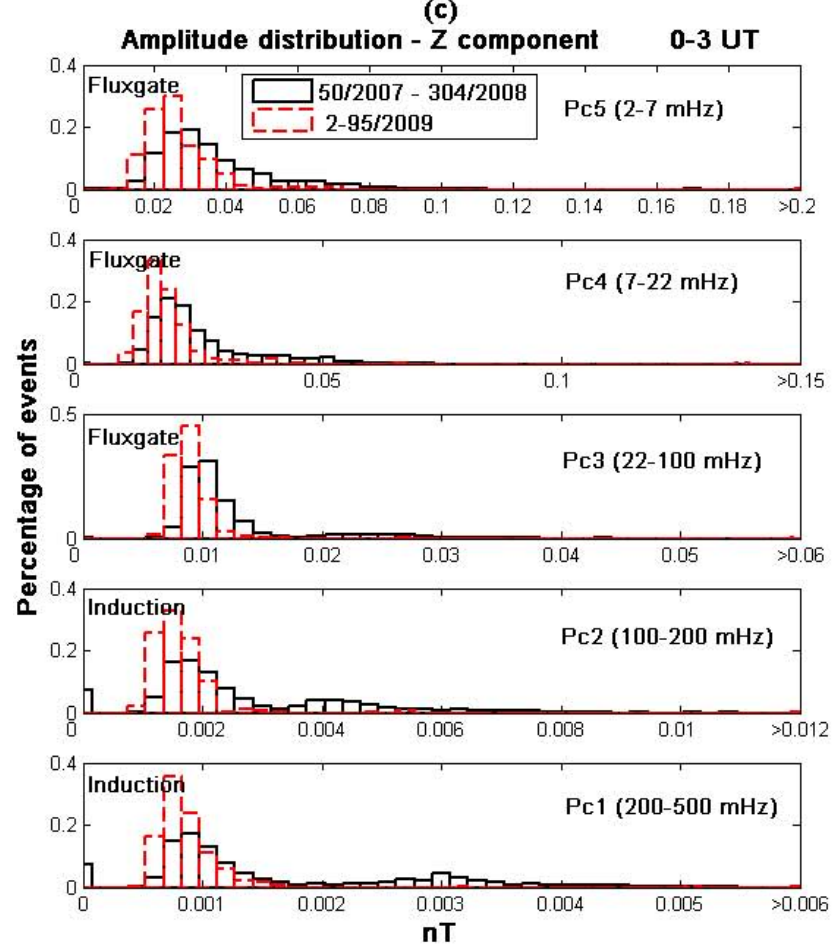

(b)
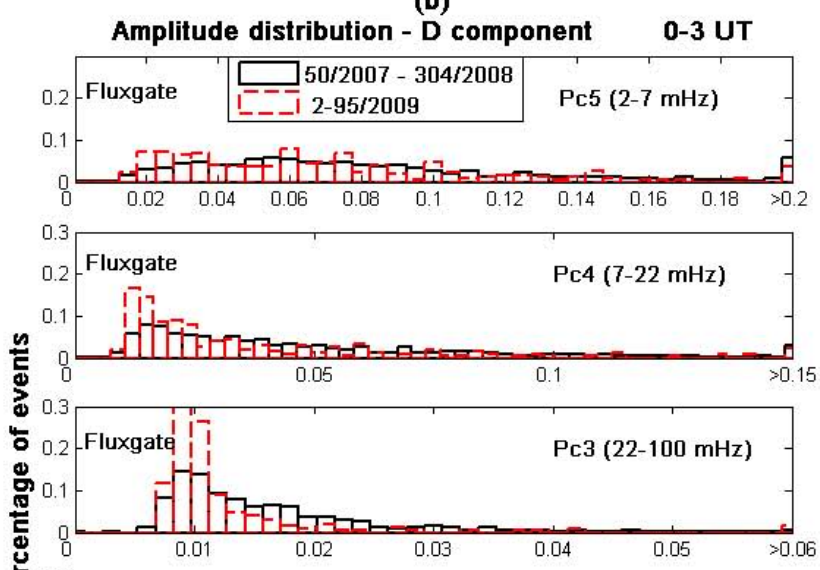

م. 0.3
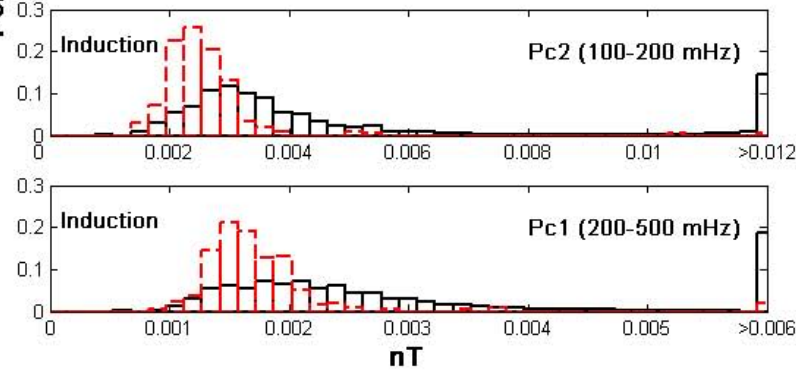

(d)
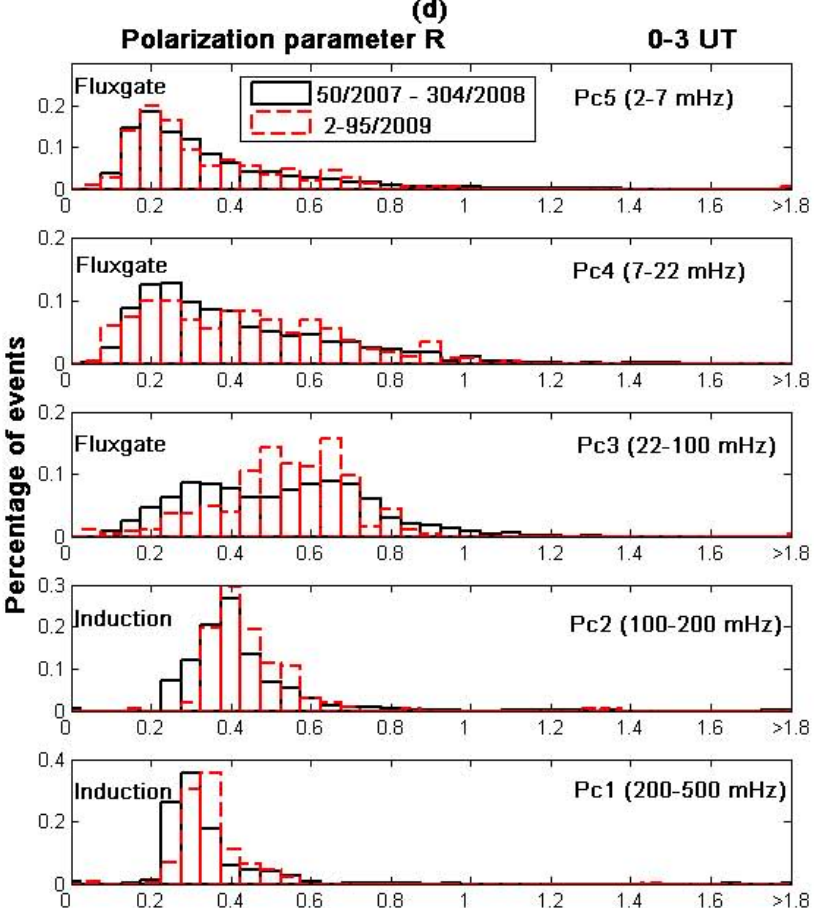

Fig. 2. Panels (a)-(c): histograms of the distributions of the amplitude of the geomagnetic field components in different frequency bands. Panel (d): histogram of the distribution of the polarization parameter $R$. Black line: data for 2007-2008; red line: data for January-5 April 2009. 
represent the effect of the instrumental noise during quiet conditions. In the lower frequency bands, $R$ shows broader distributions with higher values around $\approx 0.2$ (Pc4 and Pc5 band). For comparison, Prattes et al. (2008), who considered as polarization parameter the ratio of the power of components between $10-50 \mathrm{mHz}$, determined mean plus standard deviation values between $\approx 0.6$ and $\approx 1.2$ at three European stations. As for the field components, the comparison between different intervals does not suggest increased $R$ in the interval preceding the earthquake, although greater percentages of values between $\approx 0.4-0.7$ are detected in the Pc3 band.

\subsection{The long term behavior}

Figures $3 \mathrm{a}-\mathrm{c}$ show the long term behaviour of the amplitude of the field components and geomagnetic activity index $\mathrm{Kp}$ (six months preceding the earthquake; 00:00-03:00 UT). The close correspondence between observations obtained with different magnetometers in the Pc3-Pc5 bands (practically coincident for the $\mathrm{H}$ and $\mathrm{D}$ component) make us sure that the estimated signal amplitudes, in general, are not significantly influenced by instrumental aspects. The co-seismic shaking effect observed on the induction magnetometer measurements for the major event is practically absent in the fluxgate measurements.

A visual inspection of the experimental results suggests, with few exceptions, a general correspondence, more explicit in the Pc3-Pc5 band, between signal amplitudes and Kp index (Saito, 1969). Some evidence for higher values in the weeks preceding the earthquake (Fraser-Smith et al., 1990) might be tentatively identified in the Pc4 and Pc5 band (H component) during March 2009. However, similar increases are detected also in different intervals; in addition, it is worth noting that the peak value of the Pc5 activity (13 March) corresponds to the peak value of the Kp index in the entire six months interval.

Some prominent peaks, identified by arrows, appear in Fig. 3. Those occurring in the Pc5 band on 25 November ( $\mathrm{H}$ and $\mathrm{D}$ component, event $\mathrm{A}$ ) and on 30 December (H component, event B) might appear somewhat greater than expected, given the corresponding Kp level: nevertheless, such high values come from a wave activity (event A, Fig. 4a) and a bay-like variation (event B, Fig. 4b), respectively which are typical manifestations of the magnetospheric dynamics as observed during nighttime intervals at our latitudes. On the hand, a quick look analysis of measurements at other European observatories reveals in both cases practically the same traces. Extreme signal amplitudes are detected in all components on 11 December (event C), more explicitly in the Pc1-Pc3 band: such high values, however, basically come from an intense lightning activity (1755 lightnings within $100 \mathrm{~km}$ from AQU between 00:0003:00 UT; 186 within 50 km; SIRF-Sistema Italiano Rilevamento Fulmini, http://www.fulmini.it/default.asp; EUCLID network for lightning data for Europe, http://www.euclid. org/contacts.html\#ita) providing signal sequences such as in Fig. 4c (induction magnetometer) which mostly consist of positive and negative changes (or both) of short duration $(\approx 3-10 s)$. We would then conclude that the results of Fig. 3a-c do not reveal amplitude increases unambiguously related to the earthquake occurrence (Fraser-Smith et al., 1990; Bernardi et al., 1991; Molchanov et al., 1992; Hayakawa et al., 1996, 2000; Bleier et al., 2009).

Similarly, the polarization parameter $R$ (Fig. 3d) does not show any clear tendency to increase during weeks preceding the earthquake in any frequency band (Hayakawa et al., 1996). Nevertheless, an explicit enhancement occurs on 5 March (event D; see also Fig. 3c). The 1-s data in Fig. 4d reveal that this effect comes from a sharp variation of the geomagnetic field (affecting more explicit the vertical component with a sharp change of level of $\approx 3 \mathrm{nT}$ ) which is detected by both instruments. A similar feature might be tentatively interpreted in terms of lithospheric processes; nevertheless, the comparison with the absolute field measurements performed in situ by INGV rather suggests contamination from a highly localized artificial disturbance.

\subsection{The short term behavior}

Figure $5 \mathrm{a}-\mathrm{c}$ show the signal behaviour for the entire three days (00:00-24:00 LT) preceding the event: as can be seen, in addition to the well known daily modulation related to ionospheric and magnetospheric processes (less evident in the Pc4-Pc5 bands) as well as to man-made contamination (more explicit at higher frequencies, Villante et al., 2004), the experimental results do not reveal any increase of activity starting few hours before the earthquake (Fraser-Smith et al., 1990; Bernardi et al., 1991; Molchanov et al., 1992). Similarly, the polarization parameter (Fig. 5d), although irregular (Pc3-Pc5 band), does not show any remarkable enhancement; in addition, the lower values detected around midnight in the Pc1 and Pc2 band confirm this time interval as the most suitable for the identification of anomalous $\mathrm{Z}$ signals of lithospheric origin at the highest frequencies.

\subsection{The slope of the power spectrum and the DFA analysis}

Figure 6 shows the long term behaviour of the spectral index $\beta$ (top panel) and DFA index $\alpha$ (central panel) as obtained by a best fit linear approximation in a log-log representation of the experimental points (respectively, power density vs frequency and DFA vs. time scale). Here the data points represent the 11-days running averages of $\beta$ and $\alpha$ estimates obtained between 00:00-03:00 UT. As can be seen, the average $\beta$ typically range between $\approx 2.0$ and $\approx 2.7$ for the $\mathrm{H}$ and $\mathrm{D}$ component (consistently, $\alpha$ ranges between $\approx 1.5$ and $\approx 1.8$ ) and between 1.8 and 2.2 for the $\mathrm{Z}$ component $(\alpha$ between $\approx 1.4$ and $\approx 1.6$ ). The comparison with the behaviour 
(a)
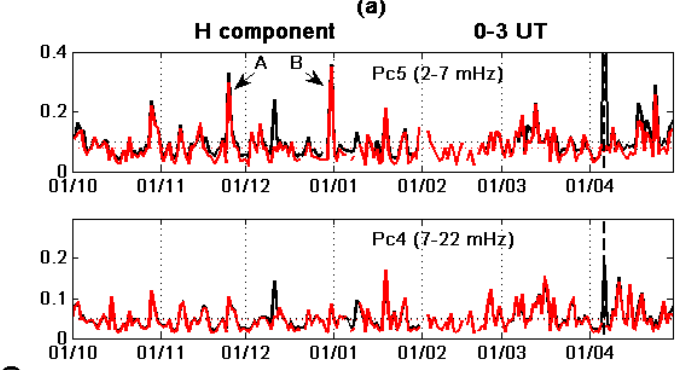

E 0 .
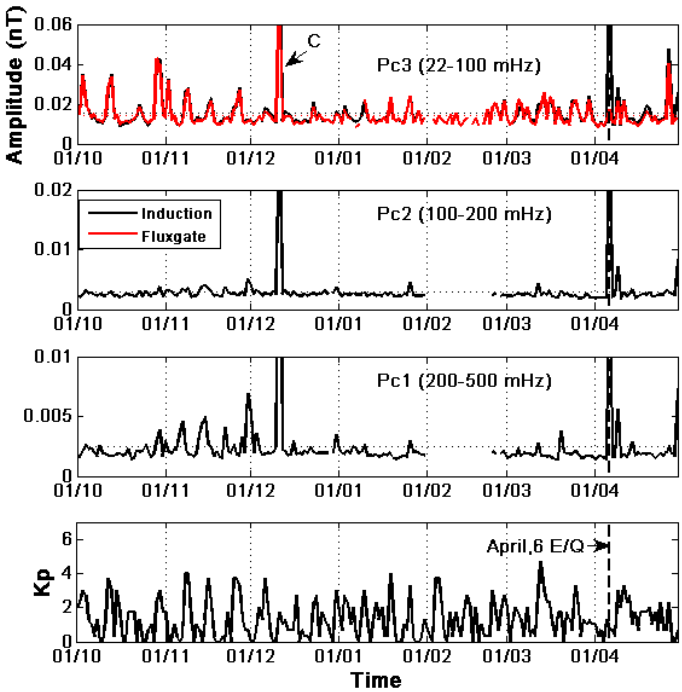

(c)
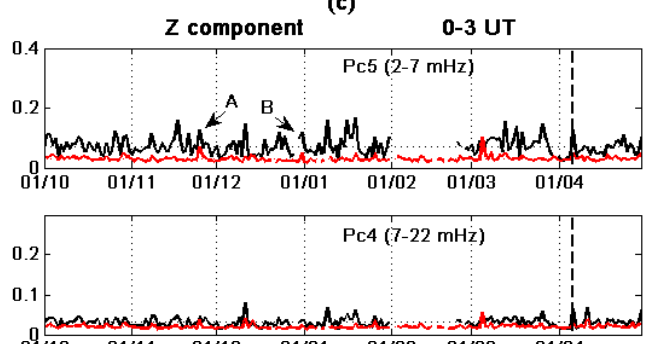

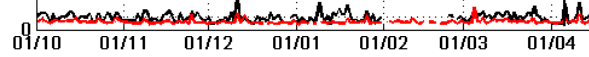

E 0.0
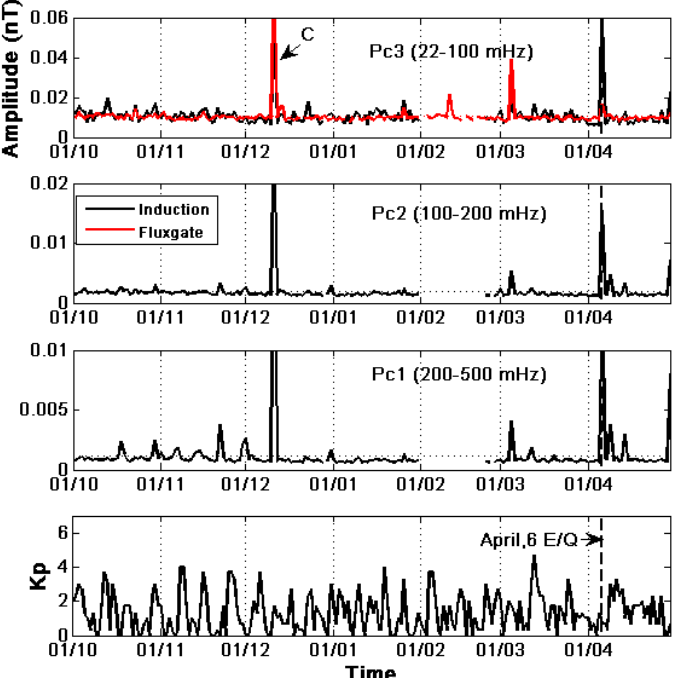

(b)
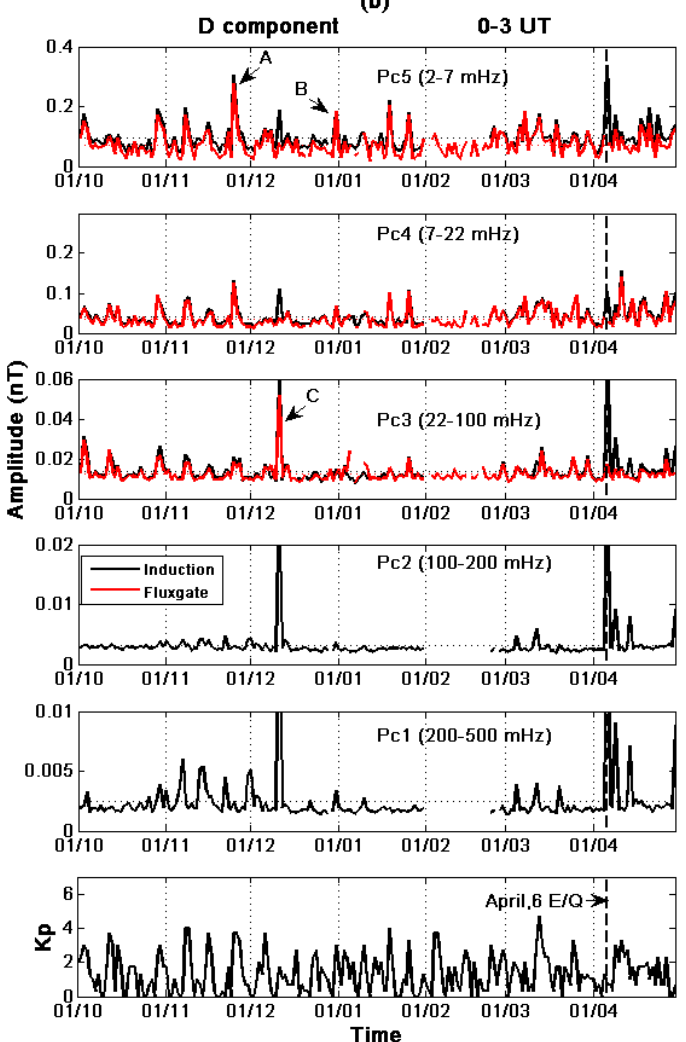

(d)
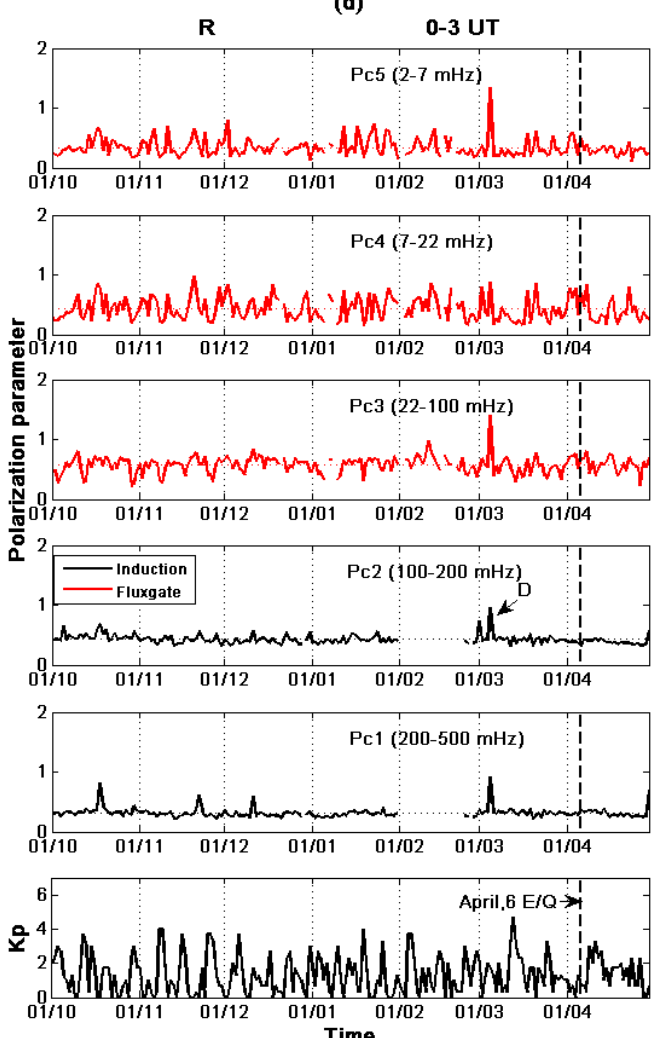

Fig. 3. Panels (a)-(c): the amplitude of components in different frequency bands (00:00-03:00 UT). Dotted lines (when identifiable) correspond to the median values. In the bottom plot: the behaviour of the Kp index. Panel (d): the polarization parameter $R$. Black line: data from the induction magnetometer; red line: data from the fluxgate magnetometer. Arrows identify events discussed in the text. 

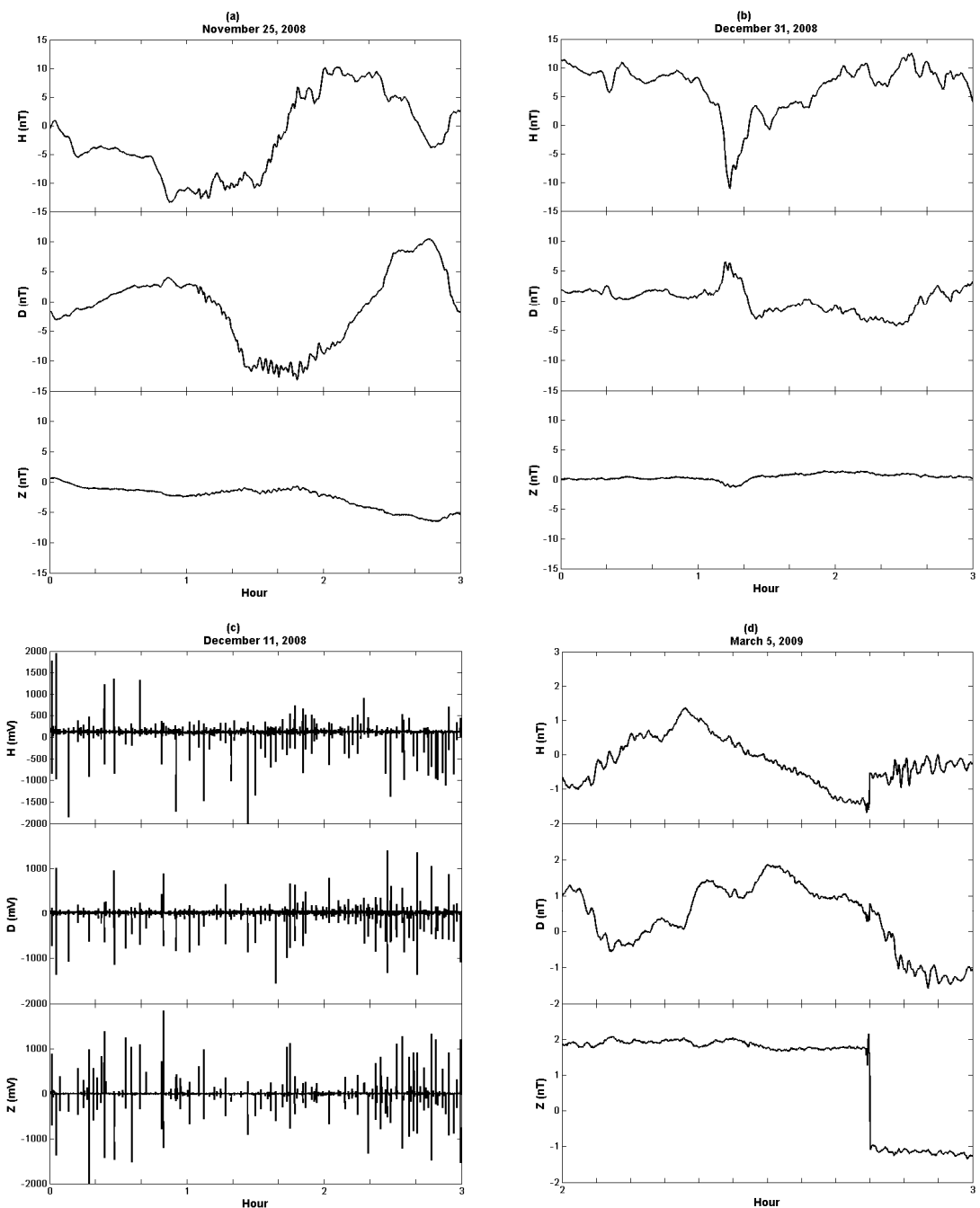

Fig. 4. Panels (a), (b), and (d): 1-s measurements from the fluxgate magnetometer. Panel (c): 1-s measurements from the induction magnetometer.

of the Kp index (bottom panel) suggests a general tendency for greater values during more active magnetospheric conditions and some evidence for a 27-day modulation (confirmed by the results of the spectral analysis, not shown; Hayakawa et al., 1996, 2000). As a matter of fact, the polynomial fit approximation of the experimental points (solid lines in Fig. 6) reveals a long term variation with smaller values of both indices approximately during summer 2007 and greater values during January-March 2008: the amplitude of such modulation is smaller for the $\mathrm{Z}$ component. In the present scenario the identification of any peculiar earthquake related feature might be highly ambiguous: in particular, we do not find any clear evidence for a gradual decrease of the slope of the power spectrum and of the DFA index in the process of earthquake preparation (1-2 months, Hayakawa et al., 1996, 2000).

\subsection{The occurrence of short duration pulses}

As previously reminded, Bleier et al. (2009) found an increased occurrence of negative or positive pulses on the D component, approximately 15 days before the Alum Rock earthquake (induction magnetometer with a $12-\mathrm{Hz}$ low pass filter); such pulses had long duration (up to $\approx 15 \mathrm{~s}$ ) as compared with that one locally determined by the lightning activity $(0.1-0.5 \mathrm{~s})$. Despite the low sampling rate $(1 \mathrm{~s})$, we found interesting to conduct a similar analysis on the induction magnetometer data, focusing attention on the daily rate of occurrence (as obtained examining the entire 24-h interval) of negative or positive pulses (or both) of short duration. A threshold of $100 \mathrm{mV}$ amplitude was used for the pulses selection; for a pulse of $4 \mathrm{~s}$ (the typical duration of the selected pulses was shorter than $\approx 5 \mathrm{~s}$ ), this threshold corresponds to a magnetic signal of amplitude $\sim 0.05 \mathrm{nT}$, well above the typical background man-made noise (less than few pT in this 

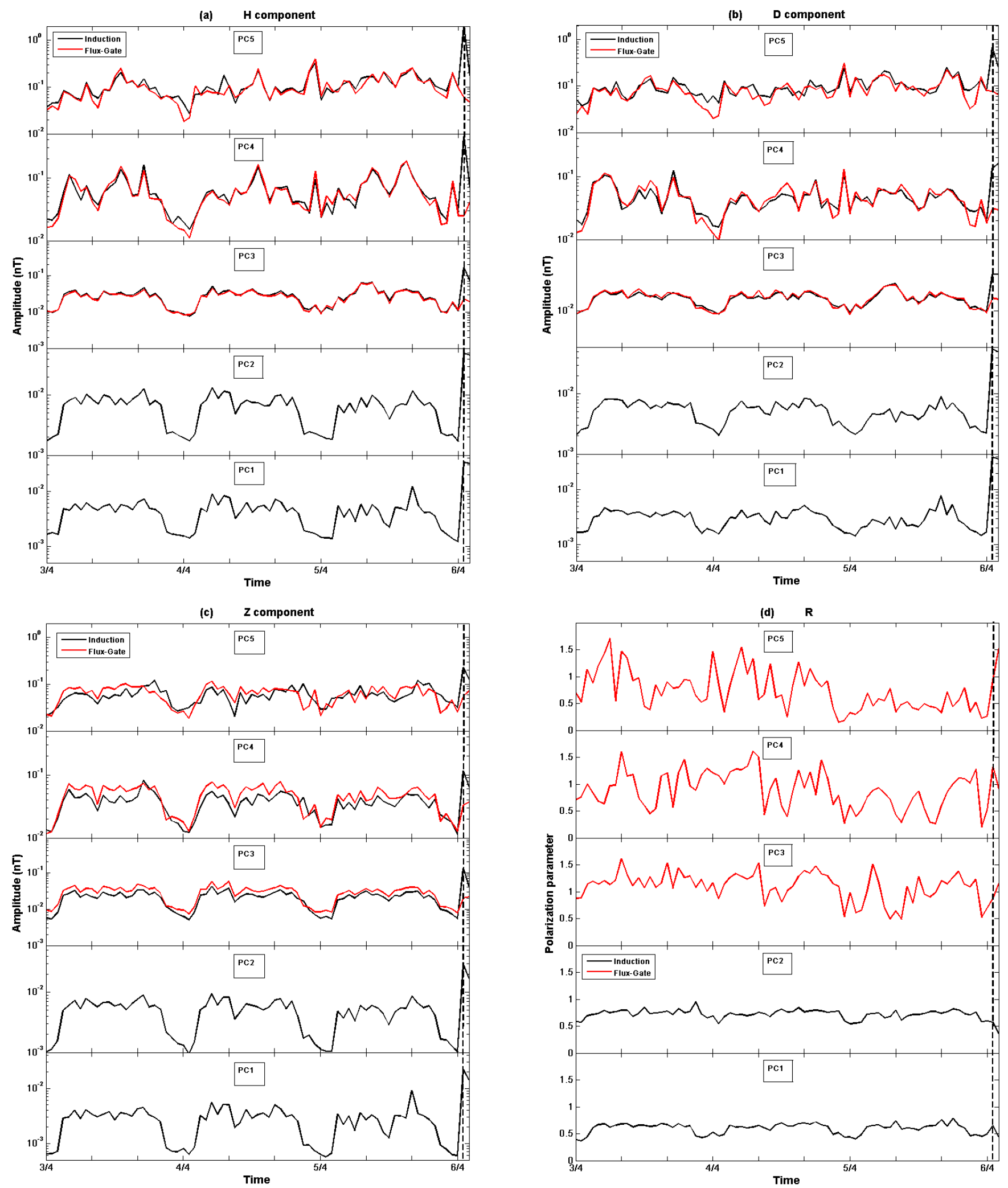

Fig. 5. Panels (a)-(c): the hourly average of the amplitude of components in different frequency bands (00:00-24:00 UT) for the three days preceding the earthquake. Panel (d): the polarization parameter $R$. Black line: data from the induction magnetometer; red line: data from the fluxgate magnetometer. The dotted lines on the right identify the earthquake occurrence. 

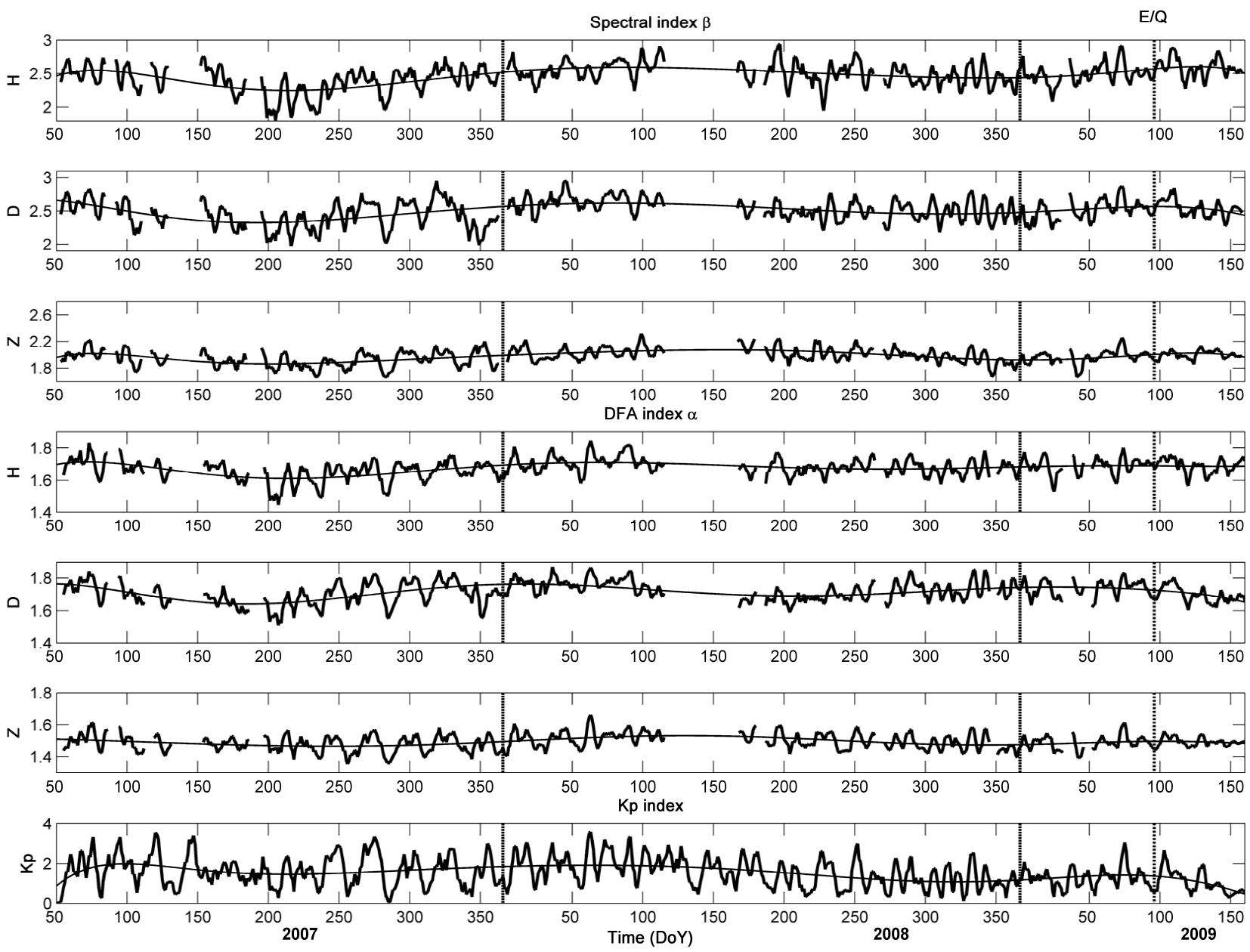

Fig. 6. Top panel: the behaviour of the spectral index $\beta$ for the field components. Central panel: the behaviour of the DFA index $\alpha$. Bottom panel: the Kp index. Solid lines identify the polynomial best fit approximation to the experimental points.

frequency range). The results of the induction magnetometer (Fig. 7; basically confirmed by fluxgate measurements) reveal a trend of the daily rate of pulses for a general increase in the time interval preceding the event, with peak values in the $\mathrm{D}$ component $\approx 20$ days before the earthquake (18 and 19 March). According to SIRF, no lightning activity occurred within $100 \mathrm{~km}$ on 18 March, while a significant lightning activity was registered between 11:28-23:30 UT on 19 March (1952 lightnings within $100 \mathrm{~km}$ ). Figure 8 shows $1 \mathrm{~h}$ of measurements for both days: on 19 March, in substantial association with the lightning occurrence, sharp pulses were detected from both the induction and the fluxgate magnetometer (with a typical amplitude smaller than $1 \mathrm{nT}$ ); on the other hand, the pulses detected on 18 March, in absence of lightning activity, reveal different features (in terms of a smaller amplitude and a tendency to be clustered in short time intervals), suggesting other natural sources or artificial contamination.

\section{Discussion}

Reliable earthquake prediction is a worthwhile goal that, if ever attained, would contribute to reduce the loss of life and property. Unfortunately, it is not at all clear that earthquake prediction is either possible and the role of geomagnetic field observations, from DC to HF, remains controversial (Johnston et al., 2006; Campbell, 2009; Thomas et al., 2009a, b; Fraser-Smith, 2009). As previously reminded, in the ULF frequency range, candidates for precursory signatures have been proposed in the increase in the noise background and polarization parameter, in the changing characteristics of the slope of the power spectrum and fractal dimension, in the possible occurrence of short duration pulses (Fraser-Smith et al., 1990; Bernardi et al., 1991; Molchanov et al., 1992; Hayakawa et al., 1996, 1999, 2000; Ida et al., 2005; Yen et al., 2004; Prattes et al., 2008; Bleier et al., 2009). It is clear, however, that, even if successfully ascertained, these elements, at the present stage, might hardly be considered as "alert" indicators of the imminent occurrence of local earthquakes; however, their unambiguous identification might be 


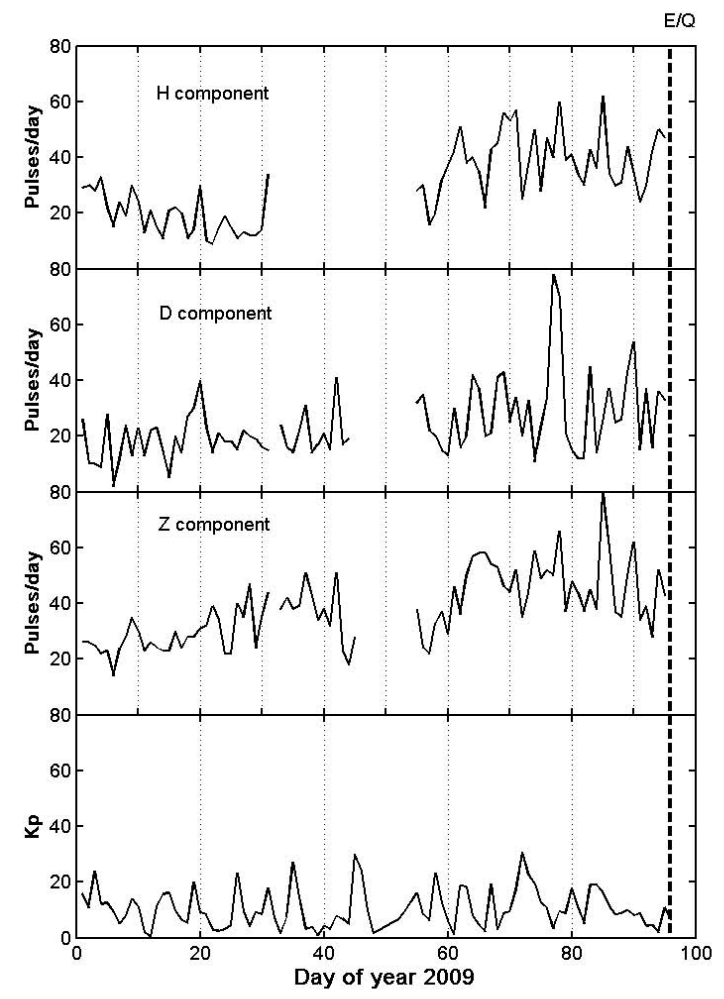

Fig. 7. The daily rate of occurrence $(24 \mathrm{~h})$ of short duration pulses in the geomagnetic field components (induction magnetometer). In the bottom panel the Kp index.

useful for a better understanding of the physical processes related to the earthquake preparation and occurrence.

On the other hand, in addition to the strength of the earthquake and to the distance of the geomagnetic measurements from the epicentre, the possible identification of earthquake related ULF signals is also remarkably influenced by the depth of the hypocenter (assuming that the sources of magnetic signals were located in and around hypocenters) and by the local electrical conductivity $(\sigma)$ of the Earth's crust. For example, Fraser-Smith (2009) estimated that a magnetic signal propagating in an "earth material" characterized by $\sigma=0.1 \mathrm{~S} / \mathrm{m}$, the signal amplitude at $\approx 0.01 \mathrm{~Hz}$ is reduced to roughly one third of its initial amplitude in $\approx 16 \mathrm{~km}$, where at $\approx 10 \mathrm{~Hz}$ this reduction takes place in only $\approx 0.5 \mathrm{~km}$. Clearly, different conductivity values would deeply alter the trend of attenuation. This is an additional feature which makes highly ambiguous the comparison between different events (note, for example, that the depth of the hypocenter was $\approx 17 \mathrm{~km}$ for the Loma Prieta event, $\approx 10 \mathrm{~km}$ at Spitak, and $\approx 50 \mathrm{~km}$ at Guam).

In this context, we conducted, with conventional techniques, a preliminary analysis of the ULF observations performed at L'Aquila during the 6 April 2009 earthquake, focusing attention on the possible occurrence of features similar to those identified in previous events. Such earthquake was not as strong as most of those examined in previous in- a) March 18, 2009 D-comp

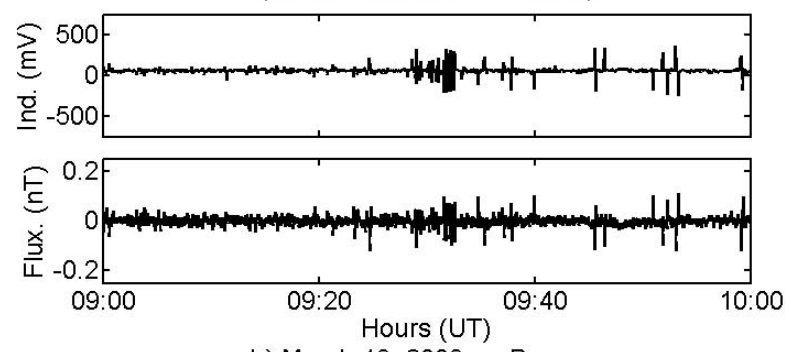

b) March 19, 2009 D-comp
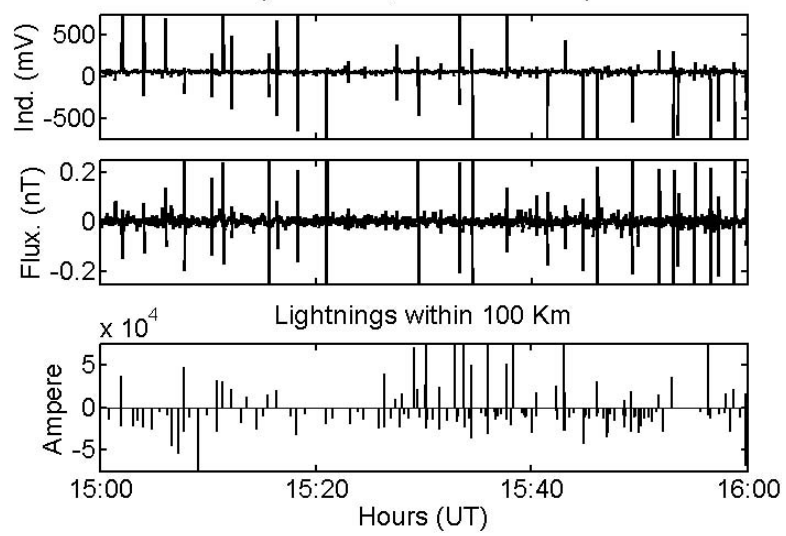

Fig. 8. 1-h samples of the comparison between the lightning occurrence and the identification of pulses in the D component in the induction and fluxgate magnetometer. Panel (a): 18 March 2009; panel (b): 19 March 2009 (no lightning activity).

vestigations: in the meanwhile, it occurred close to the local Geomagnetic Observatory (at a depth of $\approx 9 \mathrm{~km}$ ) where ULF measurements have been routinely conducted (and analysed) by different instrumentations over many years, allowing comparisons between measurements performed in the time interval preceding the event with those obtained over several years with the same instrumentation.

Within the limits of the present investigation, we did not find any compelling evidence for any of the ULF features which have been proposed as earthquake precursors, in that most of aspects of our observations (which in some cases appear consistent with previous findings are interpretable in terms of the general magnetospheric conditions or contamination by lightnings and, eventually, artificial sources. In particular, the polarization ratio identified, one month before the earthquake, a sharp change in the magnetic field elements which, in absence of careful analysis of the high resolution data and comparison with other measurements, would have been erroneously interpreted in terms of possible lithospheric processes. On the other hand, in general, caution should be adopted before drawing conclusions for similar signals. Indeed, although variations of the order of few $\mathrm{nT}$ in the geomagnetic field $(\approx 1-5 \mathrm{nT})$ have been associated with tectonic (and volcanic) activity in the Earth's crust, there are cases in which similar features can hardly be imputed to lithospheric processes (Molchanov et al., 1995b; Hayakawa and Fujinawa, 1994; Johnston, 1997; Masci et al., 2006, 2009). 
On the other hand, it is clear, that in order to ascertain the real occurrence of precursory aspects and their statistical significance, it is important to conduct preliminary analysis of the characteristics of the observing stations in terms of influence/contamination from other natural sources and man-made disturbances, relationship between the local ULF power level and the global geomagnetic activity (Kp and other indices; daily, 27-day, annual and solar-cycle modulation of ULF manifestations of external and magnetospheric origin), comparison between ground and space observations (for single events) to ascertain the possible penetration of external waves into the magnetosphere, etc. In addition, the expected ULF disturbances related to earthquakes (if any) are generally weak and sophisticated signal processing methods and a lot of experience are required to evaluate the source of ULF emission (Harada et al., 2004; Hattori and Hayakawa, 2007; Nenovski et al., 2007; Prattes et al., 2008). In forthcoming papers we will pay careful attention to these aspects: indeed, in our opinion, whatever the answer, a better understanding of the possible identification of geomagnetic signals (in general) related to earthquakes represents an important aspect which deserves significant scientific and social relevance.

Acknowledgements. This research activity at L'Aquila is supported by the Consorzio "Area di Ricerca in Astrogeofisica".

Edited by: P. F. Biagi

Reviewed by: T. Bleier and another anonymous referee

\section{References}

Anzidei, M., Boschi, E., Cannelli, V., Devoti, R., Esposito, A., Galvani, A., Melini, D., Pietrantonio, G., Riguzzi, F., Sepe, V., and Serpelloni, E.: Coseismic deformation of the destructive April 6, 2009 L'Aquila earthquake (central Italy) from GPS data, Geophys. Res. Lett., 36, L17307, doi:10.1029/2009g1039145, 2009.

Bernardi, A., Fraser-Smith, A. C., McGill, P. R., and Villard, O. G.: ULF magnetic field measurements near the epicenter of the Ms 7.1 Loma Prieta earthquake, Phys. Earth Planet. In. 68, 4563, 1991.

Bleier, T. and Dunson, C.: ELF magnetic field monitoring of the San Simeon M6.4 quake from both Quakesat and a ground network, in: Proceedings of the International Workshop on SeismoElectromagnetics, Tokyo, Japan, March 2005.

Bleier, T., Dunson, C., Maniscalco, M., Bryant, N., Bambery, R., and Freund, F.: Investigation of ULF magnetic pulsations, air conductivity changes, and infra red signatures associated with the 30 October Alum Rock M5.4 earthquake, Nat. Hazards Earth Syst. Sci., 9, 585-603, 2009,

http://www.nat-hazards-earth-syst-sci.net/9/585/2009/.

Bleier, T. and Freund, F. T.: Earthquake alarm, IEEE Spectrum, 22-27, December 2005.

Campbell, W. H.: Natural magnetic disturbances fields, not precursors, preceding the Loma Prieta earthquake, J. Geophys. Res., 114, A05307, doi:10.1029/2008JA013932, 2009.

De Luca, G., Marcucci, S., Milana, G., and Sano, T.: Evidence of low-frequency amplification in the city of L'Aquila, Central
Italy, through a multidisciplinary approach including strong- and weak-motion data, ambient noise, and numerical modelling, B. Seismol. Soc. Am., 95(4), 1469-1481, 2005.

Draganov, A. B., Inan, U. S., and Taranenko, Yu. N.: ULF magnetic signatures at the earth surface due to ground water flow: a possible precursor to earthquakes, Geophys. Res. Lett. 18, 11271130, 1991.

Egbert, G. D.: On the generation of ULF magnetic variations by conductivity fluctuations in a fault zone, Pure Appl. Geophys., 159, 1205-1227, 2002.

Fenoglio, M. A., Fraser-Smith, A. C., Beroza, G. C., and Johnston, M. J. S.: Comparison of ultra-low frequency electromagnetic signals with the aftershock activity during the 1989 Loma Prieta earthquake sequence, B. Seismol. Soc. Am., 83, 347-357, 1993.

Fenoglio, M. A., Johnston, M. J. S., and Byerlee, J. D.: Magnetic and electric fields associated with changes in high pore pressure in fault zones: application to the Loma Prieta ULF emissions, J. Geophys. Res., 100, 12951-12958, 1995.

Fraser-Smith, A. C.: The ultralow-frequency magnetic fields associated with and preceding earthquakes, in: Electromagnetic Phenomena associated with earthquakes, edited by: Hayakawa, M., Trasworld Research Network, 1-20, 2009.

Fraser-Smith, A. C.: Ultralow-frequency magnetic fields preceding large earthquakes, EOS T. Am. Geophys. Un., 89(23), p. 211, 2008.

Fraser-Smith, A. C., Bernardi, A., McGill, P. R., Ladd, M. E., Helliwell, R. A., and Villard, O. G.: Low-frequency magnetic field measurements near the epicenter of the Ms7.1 Loma Prieta earthquake, Geophys. Res. Lett., 17, 1465-1468, 1990.

Fraser-Smith, A. C., McGill, P. R., Helliwell, R. A., and Villard Jr., O. G.: Ultra-low frequency magnetic field measurements in southern California during the Northridge earthquake of 17 January 1994, Geophys. Res. Lett., 21(20), 2195-2198, 1994.

Harada, M., Hattori, H., and Isezaki, N.: Transfer function approach to signal discrimination of ulf geomagnetic data, Elsevier, Phys. Chem. Earth, 29, 409-417, 2004.

Hattori, K. and Hayakawa, M.: Recent progress and state of the art of seismo-electromagnetics, IEEJ Transactions on Fundamentals and Materials, 127(1), 4-6, 2007.

Hayakawa, M. and Fujinawa, Y. (Eds.): Electromagnetic Phenomena Related to Earthquake Prediction, TERRAPUB, Tokyo, Japan, p. 677, 1994.

Hayakawa, M., Ito, T., Hattori, K., and Yumoto, K.: ULF electromagnetic precursors for an earthquake at Biak, Indonesia on 17 February 1996, Geophys. Res. Lett., 27, 1531-1534, 2000.

Hayakawa, M., Ito, Y., and Smirnova, N.: Fractal analysis of ULF geomagnetic data associated with the Guam Earthquake on August 8, 1993, Geophys. Res. Lett., 26(18), 2797-2800, 1999.

Hayakawa, M., Kawate, R., Molchanov, O. A., and Yumoto, K.: Results of ultralow-frequency magnetic field measurements during the Guam earthquake of 8 August 1993, Geophys. Res. Lett., 23, 241-244, 1996.

Ida, Y., Hayakawa, M., Adalev, A., and Gotoh, K.: Multifractal analysis for the ULF geomagnetic data during the 1993 Guam earthquake, Nonlin. Processes Geophys., 12, 157-162, 2005, http://www.nonlin-processes-geophys.net/12/157/2005/.

Ida, Y., Yang, D., Li, Q., Sun, H., and Hayakawa, M.: Detection of ULF electromagnetic emissions as a precursor to an earthquake in China with an improved polarization analysis, Nat. Hazards 
Earth Syst. Sci., 8, 775-777, 2008,

http://www.nat-hazards-earth-syst-sci.net/8/775/2008/.

Johnston, M. J. S.: Review of electric and magnetic fields accompanying seismic and volcanic activity, Surv. Geophys., 18, 441475, 1997.

Johnston, M. J. S., Sasai, Y., Egbert, G. D., and Mueller, R. J.: Seismomagnetic Effects from the Long-waited 28 September 2004 M 6.0 Parkfield Earthquake, B. Seismol. Soc. Am., 96(4B), S206-S220, doi:10.1785/0120050810, 2006.

Kopytenko, Yu. A., Matiashvili, T. G., Voronov, P. M., Kopytenko, E. A., and Molchanov, O. A.: Detection of ultra-low frequency emissions connected with the Spitak earthquake and its aftershock activity, based on geomagnetic pulsation data at Dusheti and Vardzia, Phys. Earth Planet. In., 77, 85-95, 1993.

Little, M., McSharry, P., Moroz, I., and Roberts, S.: Nonlinear, biophysically-informed speech pathology detection, in: Proceedings of ICASSP 2006, IEEE Publishers, Toulouse, France, 2, II1080-1083, 2006.

Masci, F., Palangio, P., and Di Persio, M.: Magnetic anomalies possibly linked to local low seismicity, Nat. Hazards Earth Syst. Sci., 9, 1567-1572, 2009,

http://www.nat-hazards-earth-syst-sci.net/9/1567/2009/.

Masci, F., Palangio, P., and Meloni, A.: The INGV tectonomagnetic network: 2004-2005 preliminary dataset analysis, Nat. Hazards Earth Syst. Sci., 6, 773-777, 2006,

http://www.nat-hazards-earth-syst-sci.net/6/773/2006/.

Merzer, M. and Klemperer, S. L.: Modeling low-frequency magnetic-field precursors to the Loma Prieta earthquake with a precursory increase in fault-zone conductivity, Pure Appl. Geophys., 150, 217-248, 1997.

Miyahara, S., Tanaka, Y., Saita, K., Yumoto, K., and Tachira, H.: On ULF magnetic field variations with the Guam earthquake of 8 August 1993, in: Atmospheric and Ionospheric Electromagnetic Phenomena Associated with Earthquakes, edited by: Hayakawa, M., Terra Sci., Tokyo, 189-201, 1999.

Molchanov, O. A. and Hayakawa, M.: Generation of ULF seismogenic electromagnetic emission: a natural consequence of microfracturing process. In: Electromagnetic Phenomena Related to Earthquake Prediction, edited by: Hayakawa, M. and Fujinawa, Y., TERRAPUB, Tokyo, Japan, 537-563, 1994.

Molchanov, O. A. and Hayakawa, M.: Generation of ULF electromagnetic emissions by microfracturing, Geophys. Res. Lett., 22(22), 3091-3094, 1995a.

Molchanov, O. A. and Hayakawa, M.: On the generation mechanism of ULF seismogenic electromagnetic emissions, Phys. Earth Planet. In., 105, 201-210, 1998.

Molchanov, O. A., Hayakawa, M., and Rafalsky, V. A.: Penetration characteristics of electromagnetic emissions from an underground seismic source into the atmosphere, ionosphere and magnetosphere, J. Geophys. Res., 100(A2), 1691-1712, 1995b.

Molchanov, O. A., Kopytenko, Y. A., Voronov, P. M., Kopytenko, E. A., Matiashvili, T. G., Fraser-Smith, A. C., and Bernardi, A.: Results of the ULF magnetic field measurements near the epicenter of the Spitak $(\mathrm{Ms}=6.9)$ and Loma Prieta $(\mathrm{Ms}=7.1)$ earthquakes: comparative analysis, Geophys. Res. Lett., 19, 1495-1498, 1992.

Nenovski, P., Blagoeva, I., Vellante, M., Villante, U., Schwingenschuh, K., Boudjada, M., and Wesztergom, V.: Identification of sources of geomagnetic variations using detrended fluctuation analysis (DFA), WDS'07 Proceedings of Contributed Pa- pers, Part II, 7 pp., 2007

Park, S. K.: Precursors to earthquakes: seismoelectromagnetic signals, Surv. Geophys., 17, 493-516, 1996.

Park, S. K., Johnston, M. J. S., Madden, T. R., Morgan, F. D., and Morrison, H. F.: Electromagnetic precursors to earthquakes in the ULF bands: a review of observations and mechanisms, Rev. Geophys., 31, 117-132, 1993.

Parrot, M. and Ouzounov, D.: Surveying the Earth's electromagnetic environment from space, EOS T. Am. Geophys. Un., 87(52), p. 595, 2006.

Peng, C.-K., Havlin, S., Stanley, H. E., and Goldberger, A. L.: Quantification of scaling exponents and crossover phenomena in nonstationary heartbeat time series, Chaos, 5, 82-87, 1995.

Prattes, G., Schwingenschuh, K., Eichelberger, H. U., Magnes, W., Boudjada, M., Stachel, M., Vellante, M., Wesztergom, V., and Nenovski, P.: Multi-point ground-based ULF magnetic field observations in Europe during seismic active periods in 2004 and 2005, Nat. Hazards Earth Syst. Sci., 8, 501-507, 2008, http://www.nat-hazards-earth-syst-sci.net/8/501/2008/.

Rapolla, A., Di Fiore, V., Di Nocera, S., Matano, F., Paoletti Cugri, V., and Tarallo, V.: The April 2009 Abruzzi, Italy, Earthquake: Impact on Site Seismic Hazard Estimation, EOS T. Am. Geophys. Un., 90(45), 410-411, 2009.

Reichhardt, T.: Satellites aim to shake up quake predictions, Nature, 424, p. 478, 2003.

Saito, T.: Geomagnetic pulsations, Space Sci. Rev., 10, 319-342, 1969.

Simpson, J. J. and Taflove, A.: Electrokinetic effect of the Loma Prieta earthquake calculated by an entire-Earth FDTD solution of Maxwell's equations, Geophys. Res. Lett., 32, L09302, doi:10.1029/2005GL022601, 2005.

Surkov, V. V., Molchanov, O. A., and Hayakawa, M.: Preearthquake ULF electromagnetic perturbations as a result of inductive seismomagnetic phenomena during microfracturing, J. Atmos. Sol.-Terr. Phy., 65, 31-46, 2003.

Thomas, J. N., Love, J. J., and Johnston, M. J. S.: On the reported magnetic precursor of the 1989 Loma Prieta earthquake, Phys. Earth Planet. In., 173, 207-215, 2009a.

Thomas, J. N., Love, J. J., Johnston, M. J. S., and Kiyohumi, Y.: On the reported magnetic precursor of the 1993 Guam earthquake, Geophys. Res. Lett., 36, L16301, doi:10.1029/2009GL039020, 2009b.

Villante U. and Vellante, M.: An analysis of working days contamination in the micropulsation band, Ann. Geofis., 48, 325-332, 1998.

Villante, U., Vellante, M., Piancatelli, A., Di Cienzo, A., Zhang, T. L., Magnes, W., Wesztergom, V., and Meloni, A.: Some aspects of man-made contamination on ULF measurements, Ann. Geophys., 22, 1335-1345, 2004, http://www.ann-geophys.net/22/1335/2004/.

Yen, H.-Y., Chen, C.-H., Yeh, Y.-H., Liu, J.-Y., Lin, C.-R., and Tsai, Y.-B.: Geomagnetic fluctuations during the 1999 Chi-Chi earthquake in Taiwan, Earth Planets Space, 56, 39-45, 2004.

Zlotnicki, J., Le Mouël, J. L., Kanwar, R., Yvetot, P., Vargemezis, G., Menny, P., Fauquet, F., and Parrot, M.: Ground-based electromagnetic studies combined with remote sensing based on Demeter mission: away to monitor active faults and volcanoes, Planet. Space Sci., 54, 541-557, doi:10.1016/j.pss.2005.10.022, 2006. 